\title{
CHARLES SANDERS PEIRCE E A CONTEMPORÂNEA FILOSOFIA DA CIÊNCIA: UMA DIFÍCIL CONVERSAÇÃO ${ }^{1}$
}

Lauro Frederico Barbosa da SILVEIRA ${ }^{2}$

- RESUMO: As cada vez mais freqüentes referências ao pensamento de Peirce feitas pela contemporânea filosofia da ciência não têm sido capazes de esconder a dificuldade encontrada de assumi-lo em sua integridade. A maior parte das citações é parcial e contradiz o conjunto da doutrina. Parece ser mais fácil chamar para conversação William James e John Dewey do que chamar seu inspirador comum. A razão última deste desafio parece se encontrar na radicalidade do realismo falibilista, dificilmente aceitável pela maioria das filosofias atuais.

- UNITERMOS: Falibilismo; realismo; semiótica; conversação filosófica.

Lembrando de que a filosofia é uma ciência baseada na experiência diária...(nela) não devemos começar falando sobre idéias puras - pensamentos vagabundos que percorrem estradas desabitadas - mas devemos começar falando a respeito dos homens e de sua conversação. (Texto extraído dos Collected Papers of Charles S. Peirce. v. 8, § 112) (Grifo nosso.)

As referências ao pensamento peirceano encontradas em textos de Filosofia da Ciência, embora ainda raras, são cada vez mais freqüentes. Costumam decorrer do reconhecimento do caráter original e renovador daquele pensamento em defesa do caráter realista do conhecimento científico e ao permitir a superação de impasses decorrentes da adoção de teses herdadas do positivismo sem exigir que se aceite uma postura irracionalista. Em sua maioria, tais referências atribuem ao pensamento peirceano o mérito de conferir à experimentação e à prática científica um lugar próprio na determinação da Verdade e não desacreditar na possibilidade da representação formal de relações reais constitutivas do universo fenomênico.

1. Uma primeira versão deste texto foi apresentada no seminário "Semiótica e Interdisciplinaridade", patrocinado pelo Programa de Pós-Graduação em Semiótica e Comunicação da Pontifícia Universidade Católica de São Paulo, em 16 de junho de 1992. Parte significativa da bibliografia utilizada foi adquirida pelo programa de Auxílio Pesquisa Individual do CNPq.

2. Departamento de Filosofia da Faculdade de Filosofia e Ciências - UNESP - 17525-900 - Marília - SP. 
Entretanto, uma teoria e um método que pretendam respeitar a experiência como fundante do próprio processo lógico e ontológico do conhecimento - e não, simplesmente, de sua gênese psicológica - e como determinante da Verdade deste último, tem que assumi-lo como intrinsecamente falível sob pena de cair em contradição ou de cometer um flagrante anacronismo diante dos paradigmas vigentes da ciência. Seria contraditório afirmar a base experimental do conhecimento e negá-la ao fazê-lo indiferente à fragilidade própria de qualquer busca não fictícia; e seria desconhecer o próprio significado atual de experiência científica, recolhê-la ao domínio do inefável, conferindo à sua dimensão empírica um caráter originariamente ilusório.

As hipóteses necessárias para sustentar esta teoria e este método, respeitadas a consistência dos conceitos por elas construídos e a coerência dos procedimentos preconizados, irão se apresentar extremamente audazes ao se referirem à constituição do real e do pensamento, podendo mesmo vir a exigir a adoção de um monismo psíquico ${ }^{3}$ que viesse fundamentar, em última instância, a lei, a matéria e o próprio acaso.

Ao reconhecimento da oportunidade de um realismo científico altamente elaborado vem, assim, contrapor-se o receio dos riscos decorrentes da adoção de uma doutrina lógico-metafísica que possa comprometer demasiadamente as opções últimas da ciência e da filosofia.

No presente artigo, procurar-se-á partir de uma amostragem não exaustiva dessas referências, apontar aspectos da filosofia peirceana de difícil aceitação pelos atuais filósofos da ciência e procurar identificar as idéias centrais daquela filosofia que serviriam de base para qualquer conversação profícua que com ela quisesse se estabelecer.

\section{I}

A tese pragmatista foi e continua sendo o grande foco de atração do texto peirceano, quando evocado pela filosofia da ciência. A questão da concepção diagramática do pensamento; a especificidade do argumento abdutivo, ou retrodutivo, na construção teórica; e a abordagem epistemológica e ontológica da probabilidade e de seu tratamento estatístico também vêm recebendo o reconhecimento de vários autores, reconhecimento, contudo, acompanhado de velada restrição ao conjunto teórico ao qual pertencem.

Ainda em vida, várias vezes, sabe-se que Peirce sentiu-se constrangido a se opor aos seus melhores amigos (James, Schiller e Dewey, entre outros) para caracterizar bem sua própria doutrina e não permitir que se desviasse para o âmbito do subjetivismo psicológico, sociológico ou religioso e aí encontrar o fundamento da crença. Entre aqueles que procuraram dar prosseguimento à tese pragmatista após o falecimento de Peirce, situa-se Charles Morris ${ }^{4}$, que daquela tese elaborou uma leiture comportamentalista. Os níveis sintático, semântico e pragmático então propostos acabaram gerando três supostas áreas de conhecimento freqüentemente conflitantes 
entre si. Àqueles que adotam, mesmo que extrapolando os domínios lógico e matemático onde tem origem, a recursividade semântica de Tarski, opõe-se especialmente Karl-Otto Apel ${ }^{5}$, que julga encontrar na pragmática de uma comunidade futura de interpretação a base original da transcendentalidade para o conhecimento científico e eticamente comprometido. Há lógicos que, embora aceitem, ao lado do verdadeiro e do falso, um valor indeterminado de verdade, restringem-se à aceitação das teses de Tarski e desqualificam o domínio pragmático de qualquer pertinência formal. Uma decisão desta natureza suporia, talvez, que se verificasse a compatibilidade dos domínios da lógica formal e da semiótica de Morris. A mesma operação deveria ser realizada com o da semiótica peirceana que, como adiante será visto, difere explicitamente do da lógica, então denominada matemática.

Contrastando com esta posição, encontra-se nas obras mais recentes de Hilary Putnam a aceitação do caráter eminentemente pragmático da verdade das representações teóricas do real, quando assume como sua a tese por ele denominada de "Realismo Interno". Em Representation and Reality chega o autor a declarar que, melhor do que "Interno", o realismo oposto ao metafísico deveria denominar-se "pragmático"6. Acontece, porém, que a posição defendida esvazia os signos de qualquer capacidade de representar o real, assim como de corresponder a alguma estrutura a priori da parte de quem conhece. Colocado nesses termos, o signo designa tão-somente porque é usado.

À aceitação do pragmatismo e à multiplicidade de interpretações que dele são dadas segue-se de perto o reconhecimento da validade e da oportunidade da adoção das construções diagramáticas para representar a realidade e construir o conhecimento científico. Contemporaneamente a Peirce, assim como nos anos que se seguiram à sua morte, não somente a filosofia analítica conferia ao simbolismo formal total preferência face a qualquer recurso à imaginação, como todo o positivismo e a filosofia da ciência nele baseada, destituíam o diagrama de qualquer valor demonstrativo. A importância conferida por Peirce à herança kantiana quanto ao trabalho da imaginação na síntese do conhecimento o afasta, por exemplo, da posição assumida por Henri Poincaré e por Pierre Duhem ${ }^{7}$, a qual não conferia sequer à álgebra um papel epistemologicamente fundante do discurso científico.

Não faltaram, porém, aqueles que, como o primeiro Wittgenstein, conferiam à linguagem, e especialmente à linguagem formal, a função de construir a imagem do Mundo; como aqueles que aceitavam o peso das demonstrações ostensivas por meio de figuras e de diagramas como recurso intuitivo, independentemente da aceitação do poder representativo das demonstrações formais. O próprio, segundo Wittgenstein, crítico de si mesmo nas Investigações Filosóficas, confere valor significativo (pragmático, poder-se-ia dizer) às demonstrações ostensivas, embora nem a elas confira um substrato inquestionável de validade para as conclusões delas decorrentes.

Richard Rorty, em Philosophy and the Mirror of Nature ${ }^{8}$, reconhece em William James, Dewey, Nietzsche, Sartre e nos últimos Heidegger e Wittgenstein filósofos 
"edificantes" inovadores de questões, mas isentos da pretensão de solucioná-las. Em Descartes, Kant, Husserl e Russell, reconhece filósofos "sistemáticos", que assumem a tarefa de construir discursos explicativos do real. Se os primeiros tendem a um fazer filosófico dialogante e instigador, aos últimos caberia a sistematização e a elaboração de quadros categoriais que, com a depuração da linguagem e a clareza dos conceitos, apresentassem, para o seu tempo ou para todos os tempos, no espelho do discurso, a imagem essencial do mundo. Peirce talvez fosse colocado entre estes últimos, mas o texto, nesse momento, dele não faz menção. Menciona-o, sim, exatamente recorrendo a seu definitivo quadro categorial, ao assumir a Secundidade para representar o caráter irredutível e elementar da alteridade como fatualidade ${ }^{9}$. É de se perguntar se as categorias fenomenologicamente geradas pela teoria mais madura de Peirce incorreriam na pretensão de subjugar o mundo à Razão filosofante: caso incorressem, como então utilizá-las para expressar o que de si a elas se oporia - a fatualidade? Peirce estaria, então, não mais entre os "sistemáticos", mas, com William James e John Dewey, entre os filósofos "edificantes". Como, no entanto, isto se daria, se ele só fez crescer ao longo de sua trajetória intelectual o propósito de construir um sistema geral das ciências? Quando, porém, a obra de Rorty mais explicitamente o menciona, o faz como a um terceiro ao qual Putnam e Sellars se referem como a alguém cuja filosofia tem a coragem de estabelecer ao nível da idealidade, o fundamento do realismo. Malgrado a dificuldade de sua aceitação pelo pensador contemporâneo, preocupado em continuar compartilhando das temáticas da epistemologia e da ontologia que lhes são mais próximas, parece impor-se tal filosofia como aquela da qual não pode escapar, por via realista, quem quiser ser coerente com as exigências da própria construção teórica ${ }^{10}$. Consideração semelhante já podia ter sido encontrada, referindo-se ao idealismo transcendental; não parece claro, porém, que o realismo peirceano sob ele se localizasse, pois a subjetividade intrínseca do primeiro infirmaria o recurso, já constatado, à categoria de Secundidade ${ }^{11}$. Em seu próprio falibilismo, ao se opor ao necessitarismo, a pretensão realista do texto peircerano não é posta em questão. Parece, contudo, exigir que se aceite uma tão intensa polarização para a racionalidade que esta só se satisfaria plenamente ao se realizar na figura de uma comunidade futura localizada além dos limites da humanidade.

O reconhecimento do trabalho de Peirce na definição do argumento abdutivo ou retrodutivo como distinto da indução é, desde há muito, expresso publicamente por autores que adotam a construção de hipóteses como um momento originário do pensamento teórico. Norwood Hanson é um exemplo notável dentre esses autores pois, em Patterns of Discovery ${ }^{12}$, desenvolve, com explícita menção a Peirce, toda a fundamentação epistemológica da retrodução nos quadros da lógica da descoberta. Retoma, inclusive, o exemplo tão caro a Peirce da atribuição por Kepler da forma elíptica da órbita dos planetas como um caso notável, e mesmo dramático, de construção diagramática de hipóteses. Aos olhos de Peirce e de Hanson, o drama decorreria do fato de que tal conjectura se confrontava com as profundas convicções platônicas sobre o universo, compartilhadas pelo famoso astrônomo ${ }^{13}$. 
Noam Chomsky, no diálogo mantido com Mitsou Ronat ${ }^{14}$, embora de passagem, manifesta o mesmo reconhecimento a Peirce, dizendo tê-lo quase parafraseado em suas obras, quando necessitava tratar do levantamento de hipóteses teóricas. Valorizar, contudo, a contribuição trazida por Peirce ao argumento hipotético sem reconhecer igualmente a originalidade de sua concepção dos argumentos dedutivo e indutivo permite que se suspeite não ter o pensamento originário sido integralmente compreendido. Na proposta peirceana, os três tipos de argumentos são inseparáveis e se sustentam num fundamento comum que é a própria semiose. Por mais que tenha havido uma evolução em sua conceituação e fundamentação ao longo da gênese do pensamento peirceano, os três tipos de argumentos sempre foram tratados solidariamente, não havendo progresso no esclarecimento de um deles, sem que os outros também se beneficiassem ${ }^{15}$.

A incorporação da noção de probabilidade pela filosofia aos níveis da lógica, da epistemologia e da ontologia - inclusive, assumindo o papel a ser exercido pelo tratamento estatístico - , é tão rara mesmo na mais recente atualidade, que a iniciativa de Peirce neste sentido não pode deixar de ser reconhecida por quem se preocupa com tal questão. Patrick Suppes ${ }^{16}$, consciente dele próprio estar avançando um trabalho pioneiro, declara que só em Peirce pôde encontrar um verdadeiro predecessor. Reconhece em, no mínimo, duas passagens do texto a abordagem desmistificada do conhecimento científico adotada por Peirce, a saber: quando assume o erro inerente ao processo de mensuração, não como decorrente de uma imperfeição técnica ou de uma desatenção humana - ambas em princípio superáveis -, mas da inexorável tendência de toda medida e que cresce quanto mais precisas forem as condições de mensuração ${ }^{17}$; e quando se afasta da concepção científica como a aproximação de um quadro de verdades eternas, para reconhecê-la como essencialmente instrumental e intrinsecamente falível ${ }^{18}$.

Assumir o acaso numa metafísica voltada para o próprio exercício da ciência, declara Suppes na introdução ao seu livro ${ }^{19}$, só Peirce o fez anteriormente. E se pretende estender aquela proposta a domínios, a seu ver, não trabalhados por Peirce, como o lingüístico, não tenciona sequer a ele constantemente comparar-se, pois seu esforço será o de enfrentar a metafísica tradicional e, assim, referir-se com maior freqüência a Aristóteles, Descartes ou Kant.

Caberia, neste caso, perguntar se Peirce já não teria enfrentado tal tradição, propondo exatamente a inserção do acaso e da probabilidade nas próprias hipóteses sobre a tessitura do mundo. Por que, sem mais, declarar a intenção de não manter uma comparação mais assídua com Peirce, autor que ele mesmo reconhece como seu mais próximo predecessor?

\section{II}

Continuar insistindo em justificar a atitude furtiva dos filósofos voltados para o conhecimento científico no pouco acesso à obra peirceana ou à dificuldade encontrada 
em recuperar a substância de seu pensamento parece não mais valer para escritos tão recentes quanto a maioria dos aqui citados. Mais ainda, os autores dos referidos textos são quase todos norte-americanos, plenamente conhecedores da obra peirceana publicada, como a de seus inúmeros comentadores.

A dificuldade que se procurou detectar caracteriza-se provavelmente pela descontextualização de determinadas proposições, para assumi-las na discussão e na resolução de problemas que, freqüentemente, teriam sido melhor encaminhados pelo conjunto mais integral do pensamento peirceano. Sem intentar dirimi-la, ainda mais que não se pode afirmar que seja a única dificuldade ou que seja ela compartilhada por tão diferentes autores e em tão diferentes contextos, seria interessante retomar, embora sumariamente, o quadro da filosofia peirceana, especialmente aquele que dos últimos anos do século XIX aos primeiros do século XX consolidou-se, já que é a ele que remete a quase totalidade das contribuições reconhecidas pelos autores. Poderão ressaltar-se, então, embora como meras sugestões, alguns aspectos dificilmente aceitáveis por aqueles questionamentos.

Além dos próprios textos peirceanos publicados e de inúmeros artigos que, ao longo dos últimos anos, têm analisado com rigor múltiplos aspectos daquela obra, trabalhos baseados na análise dos manuscritos agora disponíveis, como o livro de Joseph Esposito, Evolutionary Metaphysics ${ }^{20}$ e o de Berveley Kent, Ch. S. Peirce-Logic and the Classification of $S c i e n c e{ }^{21}$, permitem que se vislumbre a problemática levantada por Peirce não só na artificial embora interessante unidade dos Collected Papers, mas perseguindo-lhe alguns veios, em seu constante fazer-se. Torna-se possível, deste modo, libertar-se das caracterizações com as quais Peirce vem sendo identificado: do detentor de um extremo imobilismo intelectual, ao qual o trabalho de toda uma vida não foi capaz de superar, ao de um autor fragmentado por diversas tendências mutuamente conflitantes, as quais se manifestariam sucessiva ou simultaneamente.

O trabalho atento de comparação dos textos como, por exemplo, o de Fred Michael a respeito da reformulação sofrida pelo conjunto do pensamento de Peirce a respeito da natureza do significado dos termos gerais a partir de 1883, com repercussões no conceito de realismo desde cedo adotado ${ }^{22}$, permite que se perceba, para vários temas centrais da obra peirceana, uma preocupação constante com a busca de uma fundamentação teórica satisfatória da realidade do conhecimento.

A formação das categorias cenopitagóricas ${ }^{23}$ e sua produção no interior da Fenomenologia, assim como a inserção desta última na classificação geral das ciências, vêm a consolidar para o próprio autor uma concepção específica de ciência como conduta racional do homem no universo. A repercussão deste feito só pode ser plenamente avaliada depois de se acompanhar, com a ajuda de Berveley Kent, o longo percurso iniciado pelo autor por volta de 1866. Percebe-se como o estatuto da lógica enquanto semiótica agora instaurado permite inseri-la no conjunto das Ciências Normativas. Como ciência geral da representação para a conduta racional no universo fenomênico, a lógica ou semiótica não necessita colocar em questão a correspondência de seus enunciados com o real para fundamentar sua verdade e nem necessita 
refugiar-se numa semântica formal, excludente de qualquer relação com um mundo exterior ao discurso. Para a filosofia peirceana, a estrita formalidade pertence originariamente à matemática e àquela lógica que a ela se reduz, as quais não necessitam referir-se a um universo de aparências para construir seus objetos. Tais ciências, contudo, só se inserirão na conduta diante do mundo fenomênico através da contribuição que trazem às ciências normativas. Sem a presença destas últimas, elas necessitam compartilhar seu domínio com o de intuições imprecisas de objetos fenomênicos.

A possível configuração do Mundo capaz de suportar tal conduta e tais representações caberá à metafísica descrever, tendo sempre em vista as objeções que lhe poderão fazer as ciências especiais em seu constante processo de investigar o modo próprio de ser das diversas classes de fenômenos experimentais ${ }^{24}$.

No interior da própria semiótica, a aplicação das categorias cenopitagóricas permitirá um desdobramento de conseqüências antes inacessíveis. Será possível, por exemplo, explicitar de modo sistemático a potência representativa do signo. Em 1903, pôde-se deduzir da definição de signo uma lista de dez classes distintas e logicamente válidas de suas possíveis realizações, depois ampliada para sessenta e seis ${ }^{25}$. Dada a genuína universalidade das categorias, permitiu-se aplicar a noção triádica de signo à totalidade do universo da experiência e promover sua verificação indutiva. O signo será distintamente atribuível desde a mera qualidade até às formas eminentemente simbólicas dos argumentos. Poder-se-ão também excluir a priori os casos incompatíveis com o domínio da experiência possível. Tal exclusão não seria possível de se realizar pela simples dedução matemática ou lógico-matemática se não se recorresse a recursos extra-sistêmicos decorrentes do senso comum ou, por uma petição de princípio, às convicções das ciências especiais. O grau de abstração característico da matemática e da lógica matemática não lhes permitiria representar um mundo real da experiência, mesmo que somente ao nível de possibilidade.

Projetada num universo fenomênico anterior a qualquer distinção entre verdadeiro e falso e entre real e fictício, e responsabilizada por somente definir as condições gerais da representatividade de um objeto futuro da conduta racional, a Semiótica supõe o trabalho da Fenomenologia, da Estética e da Ética, além do da Matemática, para constituir seu objeto. Este, com efeito, para ser representado, necessita pertencer ao universo da experiência, ser potencialmente admirável e ser efetivamente querido como a um fim.

Nenhum procedimento semiótico encontra-se excluído do domínio da racionalidade e da ciência, se por esta se entender a aprendizagem através da experiência, gerando um hábito permanente de conduta ${ }^{26}$. Tensiona-se desde o início o processo do pensamento para um futuro, já que pela representação que o determina ele é essencialmente generalizante. Esta generalização, contudo, supõe um contínuo em que o processo se efetiva, o qual não admite ruptura em qualquer momento de sua realização sob pena de seu imediato aniquilamento. 
Não se pode, portanto, supor um ser que não seja de algum modo semiótico, não constituindo apanágio de alguns o processo de pensamento ou, mesmo, alguma forma de ciência. Não se exige, tampouco, a postulação do incognoscível, se por ele se entender o que de direito escapa à possibilidade do conhecimento, seja devido a uma materialidade localizada aquém de qualquer representatividade ou uma transcendência inatingível por qualquer representação. Não são propostos o Eu transcendental ou a Coisa-em-si. Tudo o que é, é fenômeno, seja ele potencial, existente ou geral, e somente como tal torna-se sujeito e objeto de admiração, volição e conhecimento. Somente Deus, formal e não metaforicamente considerado, devido à infinita perfeição que lhe é essencial, não se constitui num ser semiótico. O pensamento divino seria imediato, excluindo o recurso a qualquer espécie de signo ${ }^{27}$.

A amplitude conferida ao domínio do pensamento não desfigura, porém, cada uma de suas possíveis realizações ou as destitui de qualquer característica que lhes seja essencial. O estrito elaborar científico e filosófico, ao qual se refere o pragmatismo como método geral de investigação, encontra-se plenamente preservado ao nível das realizações possíveis do interpretante lógico e do domínio propriamente conceitual ${ }^{28}$. O trabalho particular exigido para a elaboração da ciência e da filosofia, como o domínio do código lingüístico, a manipulação de aparelhos e ferramentas, as construções gráficas e a própria escrita, não necessita ser colocado à parte da elaboração do pensamento científico: a abstração constitutiva do símbolo não o torna indiferente às suas realizações concretas, estando elas indissociavelmente presentes no próprio ato do experimento ${ }^{29}$. A experiência como interação com o Mundo, a recusa em isolar o pensamento numa região obscura do cérebro e a incorporação das pontas dos dedos no pensamento realizado no laboratório são confirmadas por Peirce como componentes essenciais do fazer científico. Entretanto, também o é o caráter diagramático, teórico e geral do pensamento do químico, por exemplo, que experimenta mentalmente suas hipóteses a respeito da estrutura molecular da matéria, enquanto manipula calculadamente amostras das substâncias representadas à espera de verificar, na prática, uma reação prevista. De tal modo é este o procedimento do cientista que, tão logo obtenha a reação esperada, é capaz de lançar fora o produto obtido como já destituído de qualquer significado ulterior ${ }^{30}$.

Ao nível da determinação geral da conduta científica, a lógica enquanto semiótica completa o quadro das ciências. Sua articulação sistemática com as diversas ciências especiais não se faz, todavia, sem que se delineie uma hipótese sobre a constituição do Mundo como um geral real. Insiste, com efeito, Peirce em distinguir uma ciência geral cujo objeto é como devem ser todas as representações para uma inteligência capaz de aprender com base na experiência e que se insere totalmente num universo de mediações, daquelas ciências que representam seus objetos como modos especiais de ser e que, considerados não somente como aparências ou como simples determinadores da conduta que os procura - modos como são tratados, respectivamente, pela fenomenologia e pelas Ciências Normativas -, surgem como seres pura e simplesmente. 
As ciências especiais procedem à formalização lógica e matemática sem colocar a questão da possibilidade e da legitimidade de assim proceder. Aceitam o pressuposto da possibilidade de interpretar lógica e matematicamente os fenômenos por elas observados e da adequação radical de suas representações aos próprios fenômenos, desde que se respeitem os ditames formais e metodológicos da cientificidade.

As ciências não se colocam diante do dilema de adotar posições nominalistas ou realistas; no máximo, discutem a preferência por modelos dependentes de uma ou da outra posição. A filosofia, entretanto, não pode deixar de se colocar a questão da definição do estatuto epistemológico e ontológico do conhecimento, e, quando se omite em colocá-la, tal atitude não será jamais desprovida de significado. Os filósofos "sistemáticos", para retomar a terminologia de Rorty, colocam a questão de modo explícito e procuram obter-lhe uma resposta positiva. Os próprios filósofos "edificantes", ao se recusarem a enveredar na tarefa de representar o real, não o fazem sem se posicionar diante da mesma. Definem-se, freqüentemente, pela inconveniência de tal investimento ou pela denúncia do caráter ilusório e enganador que ele assume. Reconhecem, contudo, com freqüência, a validade de uma ciência cujo objeto é uma classe especial de fenômenos, opondo-se somente ao uso dogmático e metafísico dos conceitos, o qual pretende enfeixar a totalidade do real num julgamento a partir de critérios absolutos de verdade ou de eticidade.

Peirce sempre buscou elaborar uma filosofia sistemática, e seu texto, que parece para muitos incoerente com tal propósito, revela-se cada vez mais um paciente construir de um quadro conceitual, exigente quanto à consistência lógica mas, sobretudo, sensível à representação de uma realidade dinâmica e multifacetada. A unidade do discurso deveria ser alcançada sem qualquer prejuízo da infinita variedade do objeto e da integridade absoluta da verdade. A sucessão de quadros categoriais elaborados ao longo dos anos dedicados à filosofia ${ }^{31}$, de sistematizações das ciências ${ }^{32}$ e a mudança da postura assumida diante do nominalismo e do realismo ${ }^{33}$, com importantes conseqüências para o significado da proposta pragmatista, parecem suficientes para viabilizar esta tese. A tais exemplos poderiam acrescentar-se outros, tais como o das transformações ocorridas no domínio das investigações lógicas levadas a cabo por Peirce. O interesse inicialmente centrado nas figuras silogísticas desloca-se para a construção diagramática e, dentro dela, da álgebra para os grafos ${ }^{34}$. A articulação desses diversos temas e a própria aproximação das datas em que tais modificações ocorreram indicam um rumo comum daquela filosofia em busca de uma visão unificada mas não dogmática de ciência.

A adoção peirceana de uma posição crítica diante de todos os projetos teóricos, começando pelo seu próprio, fez-se exatamente no interior da preocupação de não proceder a dúvidas radicais que pretendessem iniciar ab ovo uma nova filosofia, como também de não romper deliberadamente com a tradição. A tese do contínuo do pensamento adotada por Peirce entraria em contradição com tais rupturas. Estas, caso 
ocorram, serão devidas não a uma estratégia deliberada ou a um preconceito contra o saber dos antigos, mas somente se exigidas pelo real a ser investigado. Todo saber evolui pela interferência da dúvida, mas somente de dúvidas reais que impõem ao pensador a procura de novas explicações.

A única pressuposição do projeto filosófico de Peirce, a de que a Razão não pode, sob pena de suicídio, propor o incognoscível entre seus objetos, alia-se à concepção falibilista do conhecimento e evolucionária de todo o real. Rejeita o necessitarismo sob todas as suas formas e, mais concretamente, qualquer instância indubitável no domínio do pensamento. Deste modo, é perfeitamente compreensível a preocupação peirceana com a construção sistemática da ciência teórica, nela incluídas especialmente a matemática e a filosofia. Entende-se, também, a reiteração dos problemas conjuntamente com suas soluções, e a retomada de uma terminologia tradicional às vezes, colhida no próprio texto grego ou latino - ao lado de uma proliferação de termos novos e freqüentemente bizarros em sua erudição. Ambas as preocupações não raro dificultam a leitura de um texto incessantemente preocupado em aprimorar a clareza conceitual.

\section{IV}

Não surpreende que as abordagens teóricas dos fenômenos como determinados modos de ser assumam tanto o quadro categorial, instaurado pela Fenomenologia peirceana, quanto os conceitos semióticos, e elaborem suas hipóteses integrando-os ao seu próprio questionar. Podem igualmente colher no método pragmaticista diretrizes para a conduta em suas investigações. Construir uma ciência como semiótica é um teste de singular importância para a teoria geral, que só aí pode ver apontadas suas possíveis infidelidades ao pensamento e à realidade, quer enquanto afetam a conduta em geral, quer, indiretamente, enquanto modos gerais de ser. Não se deve exigir que as ciências especiais dêem explicitamente conta da integralidade do sistema geral no qual se inspiram. Exigir-lhes tal posicionamento poderia desviá-las de seus próprios objetos de investigação e fazê-las extrapolar o método que lhes é próprio.

Quando é a abordagem filosófica que toma emprestado aspectos do pensamento peirceano e deixa na obscuridade a rede de relações em que eles se inserem e onde encontram seu pleno significado, a questão se torna mais delicada. Todo o posicionamento adotado, seja o da incorporação de propostas peirceanas, seja o de contraposição a elas, é de grande interesse. Deve-se, contudo, ressalvar que se tais posicionamentos supuserem a decontextualização das mesmas, elas assumirão o significado decorrente do contexto em que irão se inserir, não necessariamente coincidente com aquele de que originalmente eram dotadas. Estas formas de empréstimo de todo modo permitem que o diálogo filosófico se prolongue, tendo Peirce como interlocutor e conviva. 
Assumir, contudo, o pensamento peirceano de modo mais integral sem se restringir à tarefa do comentador, não parece fácil. Pretender guardar a autonomia de seu próprio questionamento e encetar um amplo diálogo com Peirce supõe dispor-se a correr o risco de ver abalados alguns pressupostos teóricos bastante arraigados no pensamento contemporâneo, sustentáculos freqüentes do discurso produzido nos círculos lógicos, epistemológicos e metafísicos.

Não há como situar-se no domínio do realismo peirceano sem aceitar, em princípio, a validade de certas teses ou de certas atitudes, tais como as que serão, em seguida, enumeradas.

1. Aceitar como válido um espírito de sistema falibilista constantemente ajustado a seu objeto por via indutiva e que não procura tomar qualquer instância transcendental na origem de sua elaboração. Não pretender, contudo, recorrer a uma classificação como um mero expediente para obter uma clareza expositiva, como poderiam aceitar o empirismo e uma filosofia indutivista. Aceitar, com efeito, que a montagem laboriosa e experimental do sistema tenha por intuito primeiro explicitar a arquitetônica do pensamento como fenômeno geral e real.

2. Excluir do sistema qualquer instância incognoscível, assumisse ela a forma do sujeito ou do objeto de conhecimento. Procedendo desta maneira, no entanto, não desacreditar da possibilidade de um conhecimento efetivo da realidade e, conseqüentemente, não concluir pelo caráter ilusório das relações objetivas, quando então o pensamento seria aceito como um simples desdobramento superficial de signos desprovidos de qualquer função representativa, somente movido por uma instância pulsional.

3. Aceitar que o Mundo possa ser concebido como uma forma em contínuo processo evolucionário de crescimento e diversificação, onde potência, existência e generalidade compartilhem do ser e definam constantemente um "telos" a ser alcançado. Aceitar a hipótese de que a realidade do Mundo seja da natureza do pensamento na qual toda a semiose encontra seu pleroma. Aceitar, conseqüentemente, a hipótese de que o pensamento a nada se oponha na constituição do Mundo e não se constitua em atributo exclusivo de alguma classe privilegiada de seres.

4. Não conferir qualquer precedência ao signo lingüístico ao se considerar o objeto da Semiótica, quando esta for tomada como uma ciência geral. Não conferir ao signo em geral o que é específico do signo lingüístico. Não reduzir, sequer, ao domínio do simbólico os demais domínios em que os signos possam se realizar. Ao se pensar a semiose, não desprezar qualquer forma de mediação que permita à conduta inteligente orientar-se para seu fim. Na perspectiva peirceana, ao simbólico cabe realizar a generalidade e a continuidade explícitas, somente a ele sendo possível determinar outros símbolos como séries infinitas de interpretantes lógicos. Não pode ele, contudo, prescindir de signos de existência e de possibilidade nem absorvê-los dialeticamente ${ }^{35}$. Estas duas outras espécies de signos compartilham com o simbólico o domínio do pensamento e do real - ambos, nesta altura, já compreendidos como sinônimos - sem nele desaparecerem ou se tornarem um resíduo não semiótico. 
Natureza e cultura, nesta concepção, não se contrapõem, não cabendo ao homem um poder soberano sobre o Universo ou o privilégio de deter consigo a mais perfeita chave da interpretação do real.

Freqüentemente, os problemas que sustentam o discurso filosófico e lhe conferem crédito ou os que radicalmente o desacreditam decorrem daqueles pressupostos que o pensamento de Peirce não assume como seus. Este pensamento apresenta, a bem da verdade, alternativas que os relativizam, superando impasses aparentemente intransponíveis. Já em 1878, com a primeira proposta da máxima pragmatista exposta em "How to Make our Ideas Clear" ${ }^{36}$, muitos destes angustiantes problemas já eram desmistificados como meros jogos de palavras capazes de encobrir significados passíveis de verificação experimental e, deste modo, não mais inefáveis. Em 1905, amadurecidas aquelas teses em "What Pragmatism is"37, o caráter falsamente metafísico daqueles problemas é denunciado como hipóstases de relações com aparência substantiva. Seria o caso, por exemplo, de substantivos como Verdade e Falsidade, que não existiriam como realidades em si mas somente relativamente à crença racional à qual se reduzem e na qual podem ser experimentalmente verificados. A verdade seria a expressão da fixação do hábito de uma conduta racional, enquanto a falsidade de uma crença anteriormente possuída decorreria da dúvida provocada por um fato adverso.

Devido ao caráter matricialmente circulatório, interpretativo e evolucionário que a Semiótica, trabalhada pela tríade categorial, confere ao pensamento, os impasses encontrados no tratamento de questões tais como as das relações entre pensamento e realidade, entre o Eu e o Mundo e, mesmo entre a lei e o acaso, como à frente se pretenderá apresentar, parecem se aliviar. Por seu lado, a adoção da lógica das relações (ou dos relativos, como preferia Peirce), em substituição à lógica centrada nas proposições e em seus termos, permitiu estender o modelo triádico do signo para um domínio ilimitadamente amplo de relações semióticas. Tais relações, dado o remetimento contínuo e evolutivo que entre si mantêm o representamen, o objeto e o interpretante, deixam de polarizar-se primordialmente em direção ao sujeito e ao predicado, para desdobrarem-se em redes indefinidamente complexas dos correlatos triádicos, como o amplo número de classes legítimas de signos, apontado anteriormente, permite verificar. O paradigma lingüístico e gramatical que se encontrava na base, desde os antigos gregos, dos quadros categoriais, finalmente é substituído pelo do diagrama de modelo topológico (gráfico ou algébrico). Descentralizou-se o estudo do signo e, com ele, do pensamento, tornando-se possível abordar qualquer domínio de representação, sem fazê-lo derivar da linguagem "verbal" e carregar consigo a matriz dicotômica, que tradicionalmente é atribuída àquela classe especial de signos.

Um sujeito transcendental ou psicológico não é pressuposto como agente anterior à síntese cognitiva nem o Mundo é representado como oposto a quem, naquela síntese, o representa. O constante remetimento de uns aos outros dos três correlatos do signo relativiza a potencialidade, a existência - e com ela, a alteridade - e a generalidade, apresentada sob a forma de lei ou de hábito. Não é possível conferir realidade a uma delas, sem dimensioná-la em relação às outras duas. A realidade é 
concebida como pertencendo à ordem do pensamento, não porque seja negado o impacto constitutivo do fato bruto mas porque este mesmo fato permite manifestarem-se qualidades que o constituem, as quais podem aparecer livremente e, porque são afeitas a ele, propiciam que, por elas, ele venha a ser representado. Esta afeição poderá ser representada na determinação de uma idéia que, interpretando-a em sua relação com o fato, fica também no lugar do fato, passa a representá-lo enquanto afeta aquela qualidade e é representado por ela. Na potencialidade espontânea da qualidade, antes da presença de qualquer sujeito dotado de transcendentalidade ou de qualquer modo de existência que defina a relação de objeto e diga de que modo efetivamente este estará representado no signo, encontra-se o fundamento primeiro da representatividade. Esta última, porém, só se completa num ciclo semiótico quando for interpretada e, por conseguinte, generalizada. Se à existência se liga a matéria e à interpretação, o pensamento, sem quebra na relação entre eles, já que ambos supõem a potencialidade que os precede e os sustenta, não há porque opô-los de modo antagônico ou redutor. Deve-se, todavia, verificar, pela infinita diversidade de qualidades característica da potencialidade, quais aquelas que se concretizam na existência como objeto do signo e quais as que constituirão representações gerais determinantes para o futuro, sob a forma de séries de interpretantes, dos hábitos inteligentes de conduta ${ }^{38}$.

Sustentando-se na espontaneidade como potencialidade positiva, a semiose inicia-se antes de qualquer relação necessitante e a ela não se limita. A primeira necessitação decorre da concretude dos fatos, os quais só serão objeto de conhecimento ao verem ressaltadas as potencialidades que compartilham com o representamen em seu fundamento e, conseqüentemente, virem relativizadas pela potencialidade do representamen as barreiras que os individualizam. Por outro lado, a necessidade decorrente da apoditicidade determinante de interpretantes lógicos, considerando-se que todas as outras determinações de interpretantes são logicamente mais fracas do que esta, projeta para o futuro as potencialidades presentes, sempre que no contínuo das interpretações um signo puder representar o objeto como classe determinada de fenômenos experimentais. Com efeito, a necessidade lógica ou a lei não excluem o acaso. Ao direcionarem a conduta ou, cosmologicamente, determinarem o rumo do próprio Universo, ela o faz num processo de constante expansão e crescimento do qual as leis necessitaristas da mecânica clássica não poderão dar suficiente conta. Pela lei semiótica e metafísica da aquisição de hábitos, toda inteligência tende para a classe de objetos representada em sua semiose, podendo percorrer, no entanto, séries disjuntas e não necessariamente excludentes de interpretação. A generalidade do objeto, que em última instância tende a se identificar com o Cosmos, poderá ser alcançada por infinitas séries de interpretantes numa convergência não necessariamente redutora, dado o caráter sempre conjectural das hipóteses por elas desenvolvidas.

Semioticamente, a poiesis parece ser um processo de desconstrução de hábitos que transforma num objeto, num gesto ou num evento singular e original, o que antes 
seria a réplica ou exemplar de uma lei geral ou de um costume. Se assim o for, a potencialidade capaz de instaurar o contínuo processo do pensamento será obtida por via poética, ao recuperar, nas estratificações já adquiridas ou em vias de aquisição, o elemento qualitativo que, no representamen, poderá ser determinado pelo objeto. Nenhuma relação no universo semiótico é suficientemente necessitada para impedir que se expresse em sua potência poética. Desta potência poderão ocorrer novas escolhas de objetos a serem procurados pelas inteligências como fins a serem alcançados no futuro. Como representação desses objetos no futuro, novos hábitos se estabelecerão e com eles novas ciências. O acaso, presença ubíqua da espontaneidade, não se perderá, assim como não se desvanecerá a admirabilidade originária do Cosmos.

Assumir com autonomia a filosofia peirceana exige não somente o reconhecimento da oportunidade de várias de suas teses, mas a adoção de um núcleo identificador de todo um pensamento. Este núcleo compõe-se de hipóteses básicas que podem e, certamente, devem sofrer desdobramentos críticos, acarretando mudanças no conjunto das teses que integram aquela filosofia. Talvez as próprias hipóteses possam vir a sofrer modificações, sem com isto desfigurar o pensamento original. No entanto, a poética que a elas subjaz e que se traduz, parece, na aposta da possibilidade irrestrita da Razão desconstruir os hábitos do Mundo, inclusive os seus próprios, terá que ser afeiçoadamente assumida. Abraçar a postura peirceana jamais consistirá na reprodução de teses de algum sistema passado ou em sua rejeição a priori; consistirá, contudo, no aprofundamento da confiança na Razão sem estabelecer-lhe qualquer limite que a impeça de expandir-se a todas as dimensões do Cosmos.

Tal adoção toma a forma de conversão intelectual, por exemplo, no caso da filósofa da matemática, Susan Haack, como relata em um seu recente artigo ${ }^{39}$. A autora mostra naquele escrito como o realismo de Peirce, cuja originalidade o distingue em última instância de todo pensamento contemporâneo, a fez abandonar os pressupostos nominalistas tão arraigados na filosofia atual e dos quais ela sempre compartilhara. Ao término do texto, declara aquilo que provavelmente acontecerá com todo aquele que se deixar honestamente tomar pelo pensamento peirceano:

Quando pela primeira vez li Peirce fiquei intrigada, e, mesmo divertida, pela ubiqüidade e paixão de seu criticismo diante do nominalismo. Fui levada a ver sua fidelidade ao realismo escolástico na melhor das hipóteses como pitoresca e, na pior, como francamente não pragmática. Agora suspeito que ele esteja à frente de nosso tempo, assim como esteve do seu.

Talvez, possa-se concluir que a conversação com Peirce só será proveitosa quando seus interlocutores conseguirem transpor a barreira de um texto de difícil acesso, no qual as mais avançadas hipóteses se entretecem com preocupações sistemáticas e expositivas nitidamente inatuais. Mais do que tudo isto, no entanto, deverão sensibilizar-se por uma Razão de tal modo inocente diante do Mundo e de si mesma, que é capaz de lançar-se com todos os recursos disponíveis na decifração de 
um enigma que só no infinitamente futuro poderá ser resolvido: um universo de idéias em constante geração e evolução, no qual a unidade e a diversidade respondem como duas faces do mesmo real.

A maior dificuldade para que se efetive esta sensibilização, sem a qual o cerne da filosofia peirceana não será atingido, parece encontrar-se no logocentrismo da cultura filosófica atual. Tomada a palavra como centro, o homem sempre se apresentará como o paradigma da realidade. Em tais condições, a radicalidade de uma filosofia estruturalmente excêntrica, pois originariamente semiótica, jamais será compreendida e integralmente assumida.

Uma conversação cósmica que satisfaça na base a busca falibilista da Verdade só será alcançada cumpridas as exigências que se tentou aqui apresentar. A partir daí, Peirce encontrará no banquete filosófico seu verdadeiro lugar.

\section{Notas}

3. Por monismo psíquico se estaria entendendo um sistema metafísico que pretendesse fundamentar, em última instância, todo o real, exclusivamente nas leis do pensamento.

4. Charles Morris explicitamente lê Peirce e a ele se contrapõe como um comportamentalista a um metafísico, tanto em Foundations of the Theory of Signs, de 1938, quanto em Signs, Language and Behavior, de 1946. Pretende constituir a Semiótica como uma ciência experimental, remetendo-a à psicologia humana ou animal. Nesse contexto, por exemplo, rejeita o emprego de "meaning" como função primordial do signo e de "conduct" como interpretante daquela função. Prefere substituí-los por conceitos, a seu ver, menos ambíguos e de melhor verificação experimental. A "meaning", substituirão dois conjuntos de termos: o primeiro é polarizado por "significatum" como processo sígnico e, o segundo, por termos denotativos do valor implicado no uso do signo (Morris, Ch., Writings on the General Theory of Signs, Paris Mouton: The Hague, 1971, p. 95, 128). Morris prefere, também, substituir o termo "conduct" por "behavior" - o que nem sempre é respeitado nas traduções -, determinando precisamente o domínio psicológico em que propõe fundamentar a Semiótica (Writings, p. 92-3, 360). Em Sign, Language and Behavior (Writings, p. 337-40), Morris posiciona-se explicitamente diante de Peirce e, embora reconhecendo a contribuição que aquele autor trouxe para a Semiótica, exige que esta perca o sentido geral e cósmico de que era dotada para transformar-se propriamente numa ciência experimental. O conceito agora proposto de ciência e de experiência nitidamente não mais coincide com o assumido por Peirce, vindo a restringir-se ao domínio do que seriam as ciências especiais ou idioscopias (Peirce, Charles S., Collected Papers of Ch.S. Peirce. Cambridge, MA. The Belknap Press of Harvard University. 1931-35. v. 1, §§238-83). Em obras posteriores, como em Signification and Significance (Morris, Ch. Signification and Significance. A study of the relations of signs and values. Cambridge, MA. MIT Press. 1964), volta-se especialmente para questões de uso e valorização dos signos sem, no entanto, rejeitar as bases estabelecidas nas obras anteriores. Assume a divisão, desde cedo proposta, entre a Sintaxe, a Semântica e a Pragmática, e trabalha especialmente 
esta última. Nesta, com efeito, o estético, o ético e o verdadeiro - como as três fontes dos valores - mais nitidamente se manifestariam ao integrarem a semiose.

5. Apel, Karl-Otto, La Transformación de la Filosofía. Madrid. Taurus. 1985. v. 1. p. 134-42, 235, 300-1; v. 2, p. 155-72, 288-99. Ver também, Apel, K-O. "Charles Sanders Peirce and the post-tarskian problem of an adequate explication of the meaning of truth: toward a transcendental theory". Part I, The Monist. La Salle, IL., v. 63, p. 386-407, 1980, Part II, Transactions of the Charles S. Peirce Society, Buffalo, NY. v. 18, n. 1, p. 3-17, 1982.

6. Putnam, H. Representation and Reality, Cambridge, MA.: MIT Press. 1989. p. 108.

7. Tiles, J. E. "Iconic Thought and the Scientific Imagination", Transactions of the Charles S. Peirce Society. v. 24, n. 2, p. 161-78, 1988.

8. Rorty, Richard Philosophy and the Mirror of Nature, Princeton, N. J.: Princeton University Press. 1979. Trad. port. Lisboa, Don Quixote, 1988.

As referências neste artigo seguirão a paginação da tradução portuguesa.

9. A Secundidade (Secondness) compartilha com a Primeiridade (Firstness) e a Terceiridade (Thirdness) do quadro das categorias universais adotado por Peirce, desde os primeiros anos do século XX. Embora aplique em sua constituição formal as propriedades mutuamente irredutíveis das mônadas, das díadas e das tríadas estabelecidas na lógica das relações, o quadro categorial agora adotado não deriva de uma análise lógica, como derivavam o quadro categorial kantiano ou o proposto por Peirce em 1867, em "The List of Categories" (Collected Papers, v. 1, §§ 545-67). Decorre, com efeito, da observação atenta de toda e qualquer aparência (fenomenon ou faneron). As três categorias correspondem aos elementos mutuamente irredutíveis que comporiam todos os fenômenos e por cuja aplicação, num número ilimitado de vezes, seria possível classificá-los como realizações do universo da experiência possível. À Primeiridade ou à propriedade elementar de ser Primeiro corresponderiam os predicados de liberdade, potencialidade positiva (e não, indeterminada) e liberdade. A ela corresponderiam, também, as qualidades de sentimento. À Secundidade, como propriedade elementar de ser Segundo ou de ser Outro, corresponderiam a fatualidade, a alteridade, a existência bruta, as relações mútuas de ação e reação, os esforços e as resistências. À Teceiridade, como propriedade elementar de ser Terceiro ou de ser Meio (Medium), corresponderiam a mediação, a lei, o hábito e o pensamento. Ao fazer com que a cada categoria corresponda um dos três primeiros números ordinais (Primeiro, Segundo e Terceiro) e permitindo que eles organizem a totalidade do universo da experiência, nele incluído tudo que é mais comum e generalizado, Peirce homenageia aos antigos gregos, quando atribuíam aos números um papel fundamental na constituição do real. Confere, pois, às três categorias a denominação de "cenopitagóricas", já que por suas propriedades numéricas elas ordenam de modo operacional e recursivo a totalidade do real fenomênico (Cf. Collected Papers, v. 1, § 351, v. 5, § 43, v. 8, § 328; Eisele, Carolyn (Ed.) The New Elements of Mathematics by Charles S. Peirce, v. 4. The Hague, Paris. Mouton. p. 307-9, 331-34). Quanto à referência de Richard Rorty à Secundidade, cf. Rorty, R. Op. cit. p. 290s.

10. Rorty, R. op. cit. p. 231s.

11. Rorty, R. op. cit. p. 230.

12. Hanson, Norwood R., Patterns of Discovery, an inquiry into the conceptual foundations of science, Cambridge, UK. Cambridge at the University Press. 1958/1977. 
13. Roberta Kelvenson, ao contrário, considera que a proposta da forma elíptica para a órbita dos planetas seria concorde com o platonismo de Kepler, já que tal forma poderia ser considerada perfeita no interior daquela doutrina. Kelvenson, Roberta, Charles S. Peirce's Method of Methods, Amsterdam/Philadelphia: John Benjamins Publishing Co. 1987, p. XII.

14. Chomsky, Noam, Dialogue avec Mitsou Ronat, Paris: Flammarion, 1977. p. 87s.

15. A solidariedade dos três tipos de argumentos no desenvolvimento do pensamento de Peirce fica especialmente patente nas transformações que experimentam quando o diagrama fundado na lógica das relações (ou dos relativos) substitui o silogismo como paradigma formal da argumentação científica. Até 1902, os argumentos hipotético, indutivo e dedutivo eram apresentados como as seguintes transformações do silogismo: Hipótese - Regra - Todos os feijões deste saco são brancos.

Resultado - Estes feijões são brancos.

Caso - Estes feijões são deste saco.

Indução - Caso - Estes feijões são deste saco.

Resultado - Estes feijões são brancos.

Regra - Todos os feijões deste saco são brancos.

Dedução - Regra - Todos os feijões deste saco são brancos.

Caso - Estes feijões são deste saco.

Resultado - Estes feijões são brancos,

(Collected Papers , v. 2, § 623.)

A partir de 1903, com a constituição da Semiótica de base diagramática, a Abdução ou Retrodução, como lógica do levantamento de hipóteses, fornecerá os dados iniciais ou premissas do diagrama, cabendo à Dedução completar a construção, quer corolariamente, pela simples constatação de propriedades contidas no diagrama mas não enunciadas na hipótese, quer teorematicamente, pelo recurso às construções realizadas no diagrama e por ele sustentadas. Caberá, por sua vez, à indução produzir as estratégias de verificação experimental das conclusões obtidas no diagrama. Distinguir-se-ão a indução ordinária, ou por simples ausência de índices opostos às conclusões obtidas pela dedução; a indução qualitativa, válida para valores, dir-se-iam, analógicos ou não denumeráveis; e a indução quantitativa, que, em sua forma mais desenvolvida, recorre à correlação estatística das variáveis. (Cf. Collected Papers, v. 2, §§ 267-70; v. 8, §§ 227-29.

16. Suppes, Patrick, Probabilistic Metaphysics, Oxford: Basil Blackwell, 1984.

17. Suppes, P., op.cit. p. 83s.

18. Suppes, P., op.cit. p. 116.

19. Suppes, P., op. cit. p. 10s.

20. Esposito, Joseph, Evolutionary Metaphysics. The development of Peirce's theory of categories, Athens, OH.: Ohio University Press, 1980.

21. Kent, Berveley, Charles S. Peirce, Logic and the Classification of Sciences, Kingston and Montreal: Mc Gill - Queen's University Press, 1987. 
22. Michael, Fred., "Two forms of scholastic realism", Transactions of the Charles S. Peirce Society, v. 24. n. 3, p. 317-48, 1988.

23. Quanto à caracterização das categorias cenopitagóricas e a justificativa de sua denominação, conferir a nota 7 .

24. Para uma abordagem minuciosa do pensamento metafísico de Peirce, consultar Ibri, Ivo Assad, Kósmos Noétós, a arquitetura metafísica de Charles S. Peirce, São Paulo: Perspectiva, 1992.

25. Peirce, Ch. S. Collected Papers, v. 1, §§ 291; v. 2, §§ 233-64; v. 4, § 530.

26. Para a filosofia peirceana e especialmente para a Semiótica, o domínio da racionalidade e o da ciência não se reduzem à produção simbólica e, menos ainda, à razão humana. Todo processo de mediação é reconhecido como racional (reasonable) e todo hábito por ele determinado pode ser denominado "científico". Em 1902, por exemplo, Peirce declara caber à Semiótica propor de maneira formal, embora eminentemente falivel, como devem ser os signos para uma inteligência "científica", isto é, para toda inteligência capaz de aprender com base na experiência. (Cf. Collected Papers, v. 2, 227).

27. Peirce, Ch. S. Collected Papers, v. 2, § 227 e Silveira, Lauro F. B. da. "Cosmos Evolutivo e Plano da Criação", Trans/form/ação. v. 8, p. 1-24, 1985.

28. Na concepção triádica de signo proposta por Peirce, o interpretante é um Terceiro que se determina relativamente ao objeto do signo através do representamen. $O$ representamen caracteriza-se por sua capacidade de colocar-se no lugar de um Outro, o qual exerce o papel de objeto ao se impor no universo fenomênico e ao se contrapor de algum modo ao representamen. O objeto, como Outro e Segundo, se oporá também ao interpretante que, por sua vez, explicitará como o representamen e ele próprio ficarão no lugar do objeto ao representá-lo. Esta representação poderá ser meramente potencial, como uma cor que por semelhança poderá ficar no lugar de qualquer objeto que igualmente a possua, dele representando precisamente a cor; como uma definição, signo de essência, que poderá caber para uma classe de objetos que sejam dotados das características nela expressas; ou mesmo, de um diagrama matemático que poderá ser aplicado a qualquer classe de objetos matemáticos ou físicos que mantiverem entre os elementos que os compõem o mesmo conjunto de relações que caracterizam o diagrama. Poderá a representação ser existencial, se a relação que mantiver com o objeto for de interação. Neste caso, o interpretante testemunhará os efeitos provocados ou sofridos pelo objeto em confronto com o representamen. Valem, como exemplos, a fumaça relativamente ao fogo, a resposta a um comando, a fotografia instantânea relativamente ao objeto fotografado, os índices no diagrama relativamente aos componentes homólogos no objeto representado, assim como os pronomes demonstrativos nas asserções para com os sujeitos designados, papel semelhante exercendo os nomes próprios. Poderá, finalmente, a representação ser geral ou, convencional, caso o representamen e o interpretante estejam no lugar do objeto em razão de uma lei ou de uma convenção. O objeto, neste caso, será necessariamente uma classe geral de fenômenos experimentais, já que será representado por uma lei geral. As inferências lógicas serão um caso típico e o melhor definido desta classe de representações e seus interpretantes constituirão a classe dos argumentos. Neste último caso, todos os interpretantes serão interpretantes lógicos e serão da natureza dos símbolos. Estes decorrem sempre de outros símbolos que se interpretam uns aos outros tendendo a constituírem séries infinitas de interpretação. Somente os interpretantes lógicos são 
necessitados no interior da semiose, sendo, pois, dotados de apoditicidade. Os demais interpretantes sempre exigirão, para sua determinação, a intervenção de um articulador não geral que permita a interpretação da relação do representamen, e a fortiori do próprio interpretante, com o objeto. A experiência é exigida no interpretante existencial para conferir sua verdade, e, no interpretante potencial, a relação da verdade ainda não se coloca. Neste caso, a relação determinante é a afeição para com o representamen e o objeto, dada a comunhão dos três em alguma qualidade comum. Para uma análise aprofundada da relação de interpretante, consultar Thibaud, Pierre, "La notion peirceénne d'interprétant", Dialectica, v. 37, n. 1, p. 3-33, 1981; Shapiro, Michael, The Sense of Grammar, Language as semeiotic. Boomington, IN.: Indiana University Press, 1983, p. 45-65; e Silveira, Lauro F. B. da, "Na Origem está o Signo", Trans/form/ação, v. 14, p. 45-52, 1991, com suas respectivas referências ao texto peirceano e à demais bibliografia.

29. Peirce, Ch. S. Collected Papers, v. 5, § 424.

30. Peirce, Ch. S., Collected Papers, v. 4, § 530; v. 5, §§ 363, 425.

31. Esposito, J., op. cit.

32. Kent, B., op. cit.

33. Michael, F., op. cit.

34. Thibaud, Pierre, La Logique de Charles S. Peirce, de l'Algebre aux Graphes, Aix-en-Provence: Eds. de l'Université de Provence, 1975.

35. Quanto ao caráter não dialético da semiose em Peirce, consultar Silveira, Lauro F. B. da, "Charles S. Peirce: Ciência enquanto Semiótica ", Trans/form/ação. v. 12, p. 71-84, 1989, nota C.

36. Peirce, Ch. S., Collected Papers. v. 5, §§ 388-410.

37. Peirce, Ch. S., Collected Papers. v. 5, §§ 411-437.

38. Procura-se aqui explicitar, recorrendo às categorias cenopitagóricas, caracterizadas respectivamente pela potencialidade, a existência e a generalidade, a exigência da semiótica peirceana de que todo signo seja um ícone ou contenha um ícone, para poder representar (Peirce, Ch. S., Collected Papers. v. 2, § 278). Este caráter originariamente icônico de todo signo permitirá a Roman Jakobson fundamentar, modalizando a tendência dominante da tradição saussureana favorável à arbitrariedade do signo lingüístico, a proposta do caráter motivado daquela classe de signos e introduzir o critério da presença ou não de marcas para organizá-la dicotomicamente (Jakobson, Roman, Lingüística e Comunicação, São Paulo. Cultrix, 1969. À Procura da Essência da Linguagem, p. 98-117 e, Jakobson, Roman e K. Pomorska, Diálogos, São Paulo: Cultrix, 1980. Cap. IX, O Tempo na Sistemática dos Signos. p. 91-2. Cap. X, O Conceito de Marca, p. 93-8). Para um estudo aprofundado das possiveis contribuições da Semiótica peirceana para a teoria lingüística, inclusive quanto à necessária iconicidade do signo lingüístico, consultar a obra anteriormente mencionada de Michael Shapiro, The Sense of Grammar.

39. Haack, Susan, "Extreme Scholastic Realism: its relevance to philosophy of science today", Transactions of the Charles S. Peirce Society, v. 28, n. 1, p. 19-43, 1992. 
SILVEIRA, L. F. B. da. Charles S. Peirce and the Contemporary Philosophy of Science: an uneasy conversation. Trans/Form/Ação, São Paulo, v. 16, p. 63-82, 1993.

- ABSTRACT: The increasingly frequent references to Peirce's thought made by the contemporary Philosophy of Science are not able to conceal the difficulty found in assuming that thought in its entireness. The most part of the quotations made are partial and contradict the whole of the doctrine. It seems easier to call James and Dewey to conversation than to call their common inspirer. The ultimate reason for this challenge seems to lie in the radicality of the fallibilist realism, hardly acceptable by almost all the present philosophical currents.

- KEYWORDS: Fallibilism; realism; semiotics; philosophical conversation. 